\title{
Preserving grapevine variety Fioletoviy Ranniy in the collection in vitro
}

\author{
Valentina Puzirnova ${ }^{1}$ and Natalia Doroshenko ${ }^{1, *}$ \\ ${ }^{1}$ Ya.I. Potapenko All-Russian Research Institute for Viticulture and Winemaking, Baklanovsky \\ Avenue, 166, Novocherkassk, 346421 Rostov region, Russia
}

\begin{abstract}
The paper is devoted to the problem of plant biodiversity conservation. This problem is acute all over the world. Lower Don Region has a centuries old history of viticulture and winemaking. There are many valuable vine varieties which are worthy of preservation for future generations. Classical methods no longer cope with this task. Applying advances of biotechnology in addition to traditional methods of ex situ and in situ biodiversity conservation allows sustainable management of genetic resources. This article summarizes the study of methods for creation slow growing collection for grapevine variety Fioletoviy Ranniy. Keeping plants in a slow-growing collection is one of the best ways to preserve biodiversity. This study analyzed the effect of various media compounds on vigor of vine in order to elongate the time between replantings.
\end{abstract}

\section{Introduction}

The problem of biodiversity conservation is not new, but despite the fact that it is paid attention at various levels from international foundations and scientific organizations to small volunteer movements for more than a decade, it is no less relevant.

In Russia, this issue is also in focus. By Decree of the President of the Russian Federation No. 204 of May 7, 2018, the conservation of biological diversity is included in the national goals and strategic objectives of the development of the Russian Federation for the period up to 2024 .

Often, when we say about biodiversity, we mean the risk to lose plant and animal species. Nevertheless, along with the reduction in the number of species, there is also a loss of varieties.

If we consider a variety as a biological object, it is born, exists for a while, then disappears - it may be lost and forgotten among the newly bred ones. The destiny of varieties is different, some varieties occupy large areas and regions and are famous all over the world, others are known only in some places or only by some specialists.

In our study, we focus on preserving the varietal diversity of grapevine, as one of the most economically significant crops in the world [1-3].

Some varieties have become well-known and beloved classics, some are familiar to a narrow number of specialists or only in one region, and others have completely disappeared.

\footnotetext{
* Corresponding author: ruswinebooks@yandex.ru
} 
Nevertheless, there are varieties that have historically grown in a particular territory. They adapted perfectly to the region, and they are valuable in terms of production. Such varieties can be arranged to national heritage and certainly need to be preserved. In addition, local varieties are carriers of unique economically valuable traits that are of particular value for breeding.

Our research focuses on the method of preserving of grapevine variety Fioletoviy Ranniy in a slow-growing collection in vitro. This variety was bred by our institute (All-Russian Research Institute for Viticulture and Winemaking named after Ya. I. Potapenko) in 1947. The wines of this variety have a wonderful soft harmonious flavor and aroma of tea rose.

Many scientific organizations all around the world are engaged into the preserving of gene pool of grapevine by creating various types of collections: in-situ and ex-situ [4-7].

The world's largest collections are in France (7,179 samples), the United States $(5,952$ samples) and India (3,900 samples) [8].

One of the oldest ampelographic collections in the world and the largest in Russia is located in the Magarach Institute (it has existed since 1814) [9].

In the North Caucasus Federal Scientific Center of Horticulture and Viticulture in the Anapa department, an extensive collection (more than 4,000 varieties) was created [10].

However, field collections are time-consuming, expensive to maintain, and prone to natural disasters. In addition, infection with pathogens, especially viruses, is common in the vine due to the vegetative propagation.

Thanks to biotechnological methods, there is an alternative method for storing genetic material - an in vitro collection, which can be used as a backup of field collections for important autochthonous varieties or as independent genetic banks [11-14].

Such collections have many advantages, the main of which are healthy virus-free plants, small occupied areas. To date, such collections have been created and are successfully conserving plants [15-16].

One of the areas of modern research in the field of in vitro collections is efficiency increasing and reduction of labor intensity and costs.

Of course, there is a price, and there is a value. And if the value of preserving the plant gene pool cannot be estimated - it is a world heritage, the price of keeping plants in the collection can be reduced. One way to reduce the costs is to store in vitro under conditions of slow growth. Maintenance of plant organs or whole plants in conditions that slow down the vigor reduces labor costs and the frequency of replantings, which may be accompanied by the risk of infection and stressful conditions that threat to genetic stability [17].

There are several methods of slowing down the growth vigor - reducing the temperature and modifying the composition of the nutrient medium [18-20].

In our work, we used the method of modifying the nutrient medium in order to reduce the growth rate of the Violet Early variety.

The aim of the study is to develop a research protocol for creating an in vitro collection, including introduction to culture in vitro, optimization of the stage of introduction, plant regeneration and selection of parameters that reduce the speed of growth processes to increase the time between replantings.

Novelty. For the first time, a scheme of introduction to in vitro culture and preparation for deposition was developed, which combines the optimization of introduction, stimulation of regeneration and slowing down the speed of growth processes for the Purple Early variety.

\section{Materials and methods}

The research was carried out according to the methods generally accepted in biotechnology by F.R. White (1949), R.G. Butenko (1964), Golodrig P.Ya. et al. (1986), N.P. Doroshenko (2012, 1992); B.A. Dospekhov (1965). The experiments were set from 2017 to 2020. 
Nutrient media was prepared from mineral and organic components, which for convenience were grouped into separate solutions of macronutrients, microelements, chelated iron, vitamins, phytohormones according to generally accepted methods in biotechnology. All studies were carried out on the Murashige and Skooga cultural media, modified for each stage of micro-propagation.

Liquid nutrient medium for introduction (mg/l). Macronutrients: $\mathrm{NH}_{4} \mathrm{NO}_{3} 1237.5 ; \mathrm{KNO}_{3}$ 1425; $\mathrm{MgSO}_{4} .7 \mathrm{H}_{2} \mathrm{O}_{2}$ 77.5; $\mathrm{KH}_{2} \mathrm{PO}_{4}$ 127.5; $\mathrm{CaCl}_{2}$. $6 \mathrm{H}_{2} \mathrm{O}$ 330.0. Micronutrients: $\mathrm{H}_{3} \mathrm{BO}_{3}$ 6.2; $\mathrm{MnSO}_{4} .4 \mathrm{H}_{2} \mathrm{OMnSO}_{4} .5 \mathrm{H}_{2} \mathrm{O}, \mathrm{MnSO}_{4} 22.3 ; \mathrm{CySO}_{4} .5 \mathrm{H}_{2} \mathrm{O} 0.025 ; \mathrm{CoCl}_{2} .6 \mathrm{H}_{2} \mathrm{O} 0.025 ; \mathrm{ZnSO}_{4} .7$ $\mathrm{H} 2 \mathrm{O} 8,6 ; \mathrm{Na}_{2} \mathrm{MoO}_{4} 2 \mathrm{H}_{2} \mathrm{O}, \mathrm{Na}_{2} \mathrm{MoO}_{4}$ 0,25; KJ 0,83. Iron chelate: $\mathrm{FeSO}_{4} .7 \mathrm{H}_{2} \mathrm{O} 27.8 ; \mathrm{Na}_{2}$ EDTA. $2 \mathrm{H}_{2} \mathrm{O}$ 37.3; $\mathrm{NaH}_{2} \mathrm{PO}_{4} 170 ; \mathrm{NaH}_{2} \mathrm{PO}_{4}$. $2 \mathrm{H}_{2} \mathrm{O}$ 221.0. Vitamins: Mesoinosit 100.0; Thiamine $\mathrm{HCl} 0.5$; 6 BAP 0.5; sucrose $30.0 \mathrm{~g} / 1$. To prepare a solid nutrient medium, $7.5 \mathrm{~g} / 1$ of agar-agar is added to its composition.

Liquid nutrient medium for proliferation of axillary buds and shoots (mg/l). Macronutrients $\mathrm{NH}_{4} \mathrm{NO}_{3} 1650 ; \mathrm{KNO}_{3} 1900 ; \mathrm{MgSO}_{4}$. $7 \mathrm{H} 2 \mathrm{O} 370 ; \mathrm{KH}_{2} \mathrm{PO}_{4} 170 ; \mathrm{CaCl}_{2} .6 \mathrm{H}_{2} \mathrm{O}$ 440. Micronutrient: $\mathrm{H}_{3} \mathrm{BO}_{3}$ 6.2; MnSO4. $4 \mathrm{H}_{2} \mathrm{O} \mathrm{MnSO}_{4} .5 \mathrm{H}_{2} \mathrm{O}, \mathrm{MnSO}_{4}$. 22.3; $\mathrm{CiSO}_{4} .5 \mathrm{H}_{2} \mathrm{O}$ 0.025; $\mathrm{CoCl}_{2}$. $6 \mathrm{H}_{2} \mathrm{O} 0.025 ; \mathrm{ZnSO}_{4} .7 \mathrm{H} 2 \mathrm{O}$ 8.6; $\mathrm{Na}_{2} \mathrm{MoO}_{4} 2 \mathrm{H}_{2} \mathrm{O}, \mathrm{Na}_{2} \mathrm{MoO}_{4}$ 0.25; KJ 0.83. $\mathrm{FeSO}_{4}$.7 $\mathrm{H}_{2} \mathrm{O}$ 27.8; $\mathrm{Na}_{2}$ EDTA. $2 \mathrm{H}_{2} \mathrm{O}$ 37.3; $\mathrm{NaH}_{2} \mathrm{PO}_{4}, \mathrm{NaH}_{2} \mathrm{PO} 4.2 \mathrm{H}_{2} \mathrm{O}$ 170, 221. Vitamins: Mesoinosit 50; Thiamine $\mathrm{HCl}$ 0.5; Sucrose $30 \mathrm{~g} /$ 1; 6-BAP 0.5-2.0; PH 5.1

Nutrient medium for rooting shoots obtained after proliferation $(\mathrm{mg} / \mathrm{l})$. Macronutrients: $\mathrm{NH}_{4} \mathrm{NO}_{3} 212 ; \mathrm{KNO}_{3} 903 ; \mathrm{MgSO}_{4} .7 \mathrm{H}_{2} \mathrm{O} 72 ; \mathrm{KH}_{2} \mathrm{PO}_{4}$ 51; $\mathrm{CaCl}_{2}$. 366. Micronutrient: $\mathrm{H}_{3} \mathrm{BO}_{3}$ 1.6; $\mathrm{MnSO}_{4} .5 \mathrm{H} 2 \mathrm{O}$ 6.0; $\mathrm{CiSO}_{4} .5 \mathrm{H}_{2} \mathrm{O}$ 0.006; $\mathrm{CoCl}_{2} .6 \mathrm{H}_{2} \mathrm{O} 0.006 ; \mathrm{ZnSO}_{4} .7 \quad \mathrm{H}_{2} \mathrm{O}$ 2.2; $\mathrm{Na}_{2} \mathrm{MoO}_{4} 2 \mathrm{H}_{2} \mathrm{O}$ 0.6; KJ 0.21; Iron Chelate: FeSO4 .7 $\mathrm{H}_{2} \mathrm{O}$ 7.0; $\mathrm{Na}_{2}$ EDTA.2 $\mathrm{H}_{2} \mathrm{O}$ 9.3; Vitamins: Mesoinosit 50; Nicotinic acid 0.2; IAC 0.1; Sucrose 10g/1; PH 5.0-5.2.

Measured values on the stage of introduction: the number of meristems less than $1 \mathrm{~mm}$, 1-3 mm, more than $3 \mathrm{~mm}$, meristems' loss from infection and due to lack of development; number of developed meristems.

Measured values during regeneration and conservation of plants: survival rate, loss due to infection, loss due to lack of development, number of roots, root length, rhizogenic zone, height, number of leaves in total and per $1 \mathrm{sm}$ of shoot, growth rate, polarity coefficient.

\section{Preparation for the stage of introducing the variety into culture in vitro}

The selection of the source material. For introduction into the culture in vitro, the shoots of the bushes of vines grown in field collections or test-tube plants obtained in laboratory conditions can be used as the source material. For cutting shoots we chose visually healthy, well-developed vines from the field collection. The presence of damage on the leaves, shoots, close internodes, the formation of two shoots from one eye, spots on the leaves, lightening of the veins of the leaves indicate diseases and are not used for creation collection.

If test tubes plants are taken as source material, we chose test tubes with well-developed plants, with straight stems, green leaves, and a clean nutrient medium. The signs of diseases are milky spots in the medium, dark spots on the surface of the nutrient medium, thinning and blackening of the roots, dryness of plants, short internodes, branching of plants.

Cuttings taken from test tube plants grown in the laboratory do not need additional disinfection. If the meristems of test tube plants are chosen as an explant for further micropropagation, the preference should be given to the buds from the lower and middle parts of the shoots, since such meristems are characterized by greater survival.

Sterilization. Cuttings taken from a field are subjected to step-by-step sterilization in the laboratory. To do this, they are cut into segments 1-2 sm long with one internode and placed in a container. 
1. Soap solution. The container with cuttings is filled with water with two drops of liquid soap and shaken for 2 minutes. The soap solution is drained.

2. Distilled water. The container with the cuttings is filled with distilled water for two minutes, shaken and drained.

3. Soak for 40 seconds in $70 \%$ alcohol.

4. In $0.8 \% \mathrm{AgNO}_{3}$ solution for $10 \mathrm{~min}$. - for mature shoots (5-7 min. - for immature shoots)

5. In the sterile box, the segments are transferred to a container with distilled sterile water and kept for 2 minutes 5 times, while changing the water.

\section{Establishment of in vitro culture}

The work on the planting of meristems, as well as its isolation was carried out in a laminar cabinet under a binocular microscope. Apical meristems were isolated from the shoots and inoculated on Murashige and Skuga nutrient medium.

The test tubes were covered with foil and placed to growth chamber for 2-3 weeks with temperature of $23-28^{\circ} \mathrm{C}$. The illumination in the first week was $800-10001 \mathrm{x}$, then it was increased to $2-5$ thousand $1 \mathrm{x}$.

In the case when meristems are isolated from cuttings of field plants, the MS medium is supplemented with Ribavirin at a concentration of 5-10 mg / , Cefotaxime 100-200 mg/l and Melafen at concentrations of $10^{-7}-10^{-9}$. Ribavirin and Cefotaxime are added to the medium after its sterilization and cooling to $50^{\circ} \mathrm{C}$.

\section{Proliferation stage}

When the meristems reach a size of $3 \mathrm{~mm}$ or more, they are subcultured to a liquid medium to pass the proliferation stage in conical Erlenmeyer flasks $(100 \mathrm{ml})$ with bridges made of filter paper. Subcultures of explants to a fresh nutrient medium were carried every two weeks.

Rooting of shoots and single-eyed cuttings. After shoots 20-25 mm height with 3-5 leaves grew, they were separated from the conglomerates and planted for rooting on a solid MS nutrient medium with a reduced content of macronutrients. Rooting of shoots was carried out at an illumination of 3-5 thousand lux for 14-16 hours at a temperature of $20-25^{\circ} \mathrm{C}$ in the dark and $25-30^{\circ} \mathrm{C}$ in the light periods.

\section{In vitro micropropagation}

Test tube plants grown in vitro are divided into single-node micro-cuttings, which are used as secondary explants. Micro-cuttings are planted on a modified MS medium with a reduced content of IAA and macronutrients. The optimal placement of the micro-cuttings is tilt position, and size is $0.8 \mathrm{sm}$.

When choosing an explant for micro-cutting, you should give preference to the upper part of a shoots. Studies have shown that plants initiated from the upper part of a shoot have good survival rate (up to $100 \%$ ) and preservation (up to 340 days). At the same time, there is a moderate development of the rhizogenic zone, shoots, and foliage in plants from the upper part of the shoots, which is especially important when creating a slow-growing collection

At this stage, the nutrient medium is optimized to reduce the intensity of growth processes. Antibiotics are used not only to fight a disease but also to effect the growth vigor. Clonal micro-propagation of plants is often accomplished with a risk of internal bacterial infections. Sometimes contamination is a direct consequence of the use of an infected explant. In addition, the components of the nutrient media can be a source of contamination. A real and common source of contamination is intra-laboratory transmission of infection 
from the air, from personnel, from the laboratory preparations used, and from one cell culture to another. Joint cultivation of contaminated and mycoplasma-free cells in the same room leads to infection of a healthy one after 1-2 passages. In this case, antibacterial chemotherapy is carryied out. The use of antibiotics is based on their ability to inhibit the development of pathogenic microflora. In addition, antibiotics, like other microbial metabolites, can directly affect the metabolism and development of plants.

We recommend one of the following antibiotics to suppress bacterial infections and slow down growth processes: Gentamicin at a concentration of $0.01 \mathrm{ml} / 1$, Cefotaxime at a concentration of $300 \mathrm{mg} / \mathrm{l}$.

Carbohydrates in the nutrient medium are the source of energy for cultivated plants and the main osmotic agent. Among the biotechnological methods of creating conditions for slow growth is the use of osmotics. Osmotics are substances that create a lack of moisture for a plant. Sucrose is widely used as an osmotic.

The study of the effect of sucrose concentration on the growth and development of Purple Early vine demonstrates a high survival rate (Table 1). Concentration of $20 \mathrm{~g} / 1$ was a control. The highest survival rate was observed at a concentration of $60 \mathrm{~g} / 1-82.1 \%$; in the control $75.0 \%$. At the minimum concentration, the length of the rhizogenic zone decreased. Similarly, the height and leafiness of the plants changed: it increased at a concentration of 60 $\mathrm{g} / \mathrm{l}$ and decreased at a concentration of $5 \mathrm{~g} / \mathrm{l}$. Thus, when the concentration of sucrose in the nutrient medium is $5 \mathrm{~g} / 1$, growth processes are inhibited.

Table 1. Sucrose effect on growth vigor of grapevine Fioletoviy Ranniy, 2018-2019

\begin{tabular}{|c|c|c|c|c|c|}
\hline \multirow[b]{2}{*}{ Concentration, g/l } & \multirow[b]{2}{*}{ Survival, \% } & \multicolumn{2}{|c|}{ Roots } & \multirow[b]{2}{*}{ Shoot, sm } & \multirow[b]{2}{*}{$\begin{array}{c}\text { Growth vigor, } \\
\text { mm / day }\end{array}$} \\
\hline & & $\begin{array}{c}\text { Number, } \\
\text { pes. }\end{array}$ & Length, sm & & \\
\hline \multicolumn{6}{|c|}{50 days of cultivation } \\
\hline Control & 100 & 1.1 & 3.9 & 2.7 & 0.5 \\
\hline 5 & 100 & 1.5 & 1.9 & 2.3 & 0.5 \\
\hline 40 & 100 & 1.5 & 4.6 & 3.0 & 0.6 \\
\hline 60 & 96.4 & 1.0 & 5.2 & 3.2 & 0.6 \\
\hline $\mathrm{HCP}_{0,95}$ & & - & 0.3 & - & \\
\hline \multicolumn{6}{|c|}{120 days of cultivation } \\
\hline Control & 82.1 & 1.1 & 4.9 & 10.8 & 0.9 \\
\hline 5 & 78.6 & 1.5 & 2.2 & 6.5 & 0.5 \\
\hline 40 & 71.4 & 1.7 & 5.6 & 11.9 & 1.0 \\
\hline 60 & 89.3 & 1.2 & 6.6 & 12.2 & 1.0 \\
\hline $\mathrm{HCP}_{0,95}$ & & - & 0.7 & 2.5 & \\
\hline \multicolumn{6}{|c|}{205 days of cultivation } \\
\hline Control & 51.7 & 1.1 & 4.6 & 15.2 & 0.7 \\
\hline 5 & 42.9 & 1.6 & 2.5 & 10.7 & 0.5 \\
\hline 40 & 42.9 & 1.6 & 5.2 & 15.3 & 0.7 \\
\hline 60 & 64.3 & 1.2 & 6,2 & 15.8 & 0.8 \\
\hline $\mathrm{HCP}_{0,95}$ & & - & 1.4 & 1.6 & \\
\hline \multicolumn{6}{|c|}{301 days of cultivation } \\
\hline Control & 53.6 & 1.1 & 4.7 & 16.2 & 0.5 \\
\hline 5 & 42.9 & 1.6 & 3.1 & 11.5 & 0.4 \\
\hline 40 & 32.1 & 1.6 & 5.3 & 16.2 & 0.5 \\
\hline 60 & 46.4 & 1.5 & 7.6 & 17.0 & 0.6 \\
\hline $\mathrm{HCP}_{0,95}$ & & - & 1.4 & 2.3 & \\
\hline
\end{tabular}

The highest survival rate after 10 months of study was in the variant with a concentration of $60 \mathrm{~g} / \mathrm{l}$. The largest rhizogenic zone throughout the experiment was in a concentration of $40 \mathrm{~g} / \mathrm{l}$, and the shoot length - in the variant of $60 \mathrm{~g} / \mathrm{l}$. The growth rate also increased with increasing concentration. Thus, to keep plants in slow growing collection low sucrose concentrations are recommended. 
Fructose or fruit sugar $\mathrm{C}_{6} \mathrm{H}_{12} \mathrm{O}_{6}$ is a monosaccharide - a part part of sucrose. Our study have proved that preservation of vine on the medium with fructose inhibits of shoot growth. The slowest growth rate was at fructose concentrations of 20.0, 40.0, and $60.0 \mathrm{~g} /$, but survival rate also decreased. It indicates toxicity such amount of carbohydrate $(60,0-40 \mathrm{~g} / \mathrm{l})$ in the medium for vine

More than half of the plants $(60,0 \%)$ survived at concentrations of fructose of 10.0 and $20.0 \mathrm{~g} / 1$

When comparing sucrose (control $20.0 \mathrm{~g} / \mathrm{l})$ and fructose $(20.0 \mathrm{~g} / \mathrm{l})$, it can be seen that sucrose more contributed to the preservation of plants $(86.7 \%)$ than fructose $(60.0 \%)$. At concentrations of 5.0 and $10.0 \mathrm{~g} / \mathrm{l}$, the growth of shoots was close to the control one.

During the first 4 months of cultivation, the survival rate of micro-gears and the safety of micro-plants was higher in the variants with fructose in the amount of $5.0 ; 10.0 ; 20 \mathrm{~g} / 1$. A sharp decrease in survival rate occurred at a fructose concentration of $60.0 \mathrm{~g} / \mathrm{l}$. In this variant, the survival rate from the first month of cultivation and throughout the entire experiment is low (6.7-3.3\%). After 6 months of cultivation, the plants in all variants of the experiment stopped growing, the leaves turned yellow and dried up, and their death occurred.

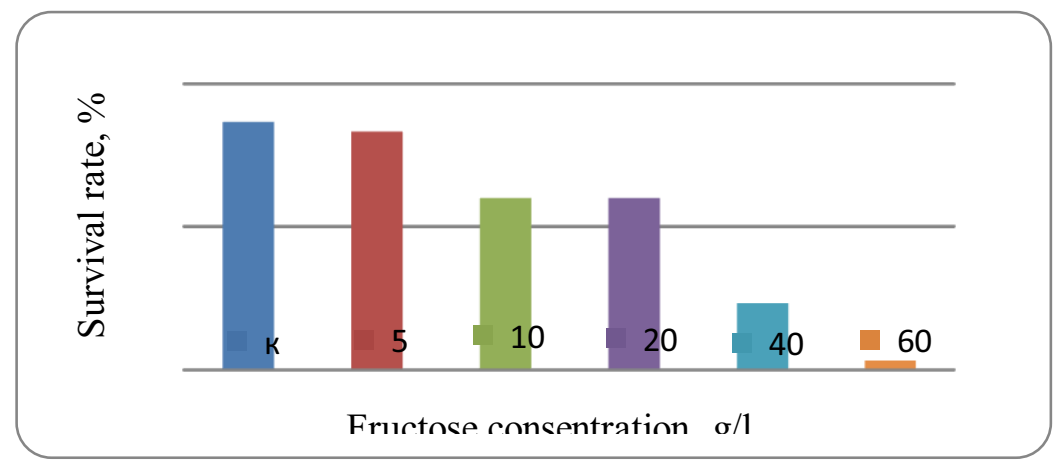

Fig. 1. Vine's survival rate after 210 days of cultivation

The figure clearly shows that the best safety of the vine during the 7 months of cultivation revealed on the medium with sucrose (control) and the minimum concentration of fructose $5.0 \mathrm{~g} / \mathrm{L}$.

\section{Conclusions}

Based on four years of research, a protocol for creating an in vitro genetic collection consisting of three blocks has been developed:

1. Preparation and introduction of plants into culture (a - from vine shoots of the field collection; $b$ - from plants grown in vitro);

2. Regeneration, propagation, preparation of vine for preservation;

3. Formation of a slow-growing collection, based on the modification of nutrient media with the help of antibiotics and alternative sources of carbohydrates.

Based on the study, the duration of keeping vine in the collection without replantings increased up to 10-12 months and more, which contributes to maintaining the genetic stability of grapevine plants and increases the economic efficiency of preservation.

\section{References}

1. A. A. Al-Aizari, R. S. Al-Obeed, M.A.H. Mohamed, Electronic Journal of Biotechnology 48, 95-100 (2020) 
2. S. Tehrim, G. M. Sajid, Biotechnological Letters 16, 6, (2011)

3. W.-L. Bi, C. Pan, X.-Y. Hao, et al. In vitro cellular \& developmental biology 53(5), 449-460 (2017)

4. E. Maletić, I. Pejić, J. Karoglan Kontić, G. Zdunić et al., Vitis 54, 93-98 (2015)

5. C. Yuan, W. Dong Yan, Z. BaoLin, W. YueJin, W. Ying Qiang, Journal of Fruit Science 34(8), 968-976 (2017)

6. K. Margaryan, E. Maul, Z. Muradyan et al. BIO Web Conf. 12 (2019) https://doi.org/10.1051/bioconf/20191201002

7. I. Tsvetkov, T. Dzhambazova, V. Kondakova, R. Batchvarova, Universal Journal of Plant Science 2(2), 48-51 (2014) DOI: 10.13189/ ujps.2014.020204

8. E. Dettweiler, P. This, R. Eibach, XXV Congres mondial de la vigne et du Vin, Franse, $1-10$ (2004)

9. V.A. Polulyakh, V.V. Volynkin, V. Likhovskoi, Journal of Genetics and Breeding 21(6), 608-616 (2017)

10. V.A. Bolshakov, A.A. Lukyanova, A.G. Kovalenko, Science life 10, 126-133 (2018)

11. F.K. Pilatti, T. Aguiar, T. Simões, et al. In Vitro Cell.Dev.Biol.-Plant 47, 82-98 (2011) https://doi.org/10.1007/s11627-010-9302-y

12. B.M. Reed, V. Sarasan, M. Kane, E. Bunn, V.C. Pence, In Vitro Cellular and Developmental Biology - Plant 47(1), 1-4 (2011)

13. F. Engelmann, Use of biotechnologies for the conservation of plant biodiversity. In vitro Cellularand Developmental Biology - Plant 47, 5-16 (2011)

14. A.V. Deepa, T.D. Thomas, In Vitro Cell.Dev.Biol.-Plant. 56, 784-802 (2020) https://doi.org/10.1007/s11627-020-10084-x

15. H. Barnicoat, R. Cripps, J. Kendon, V. Sarasan, In Vitro Cell. Dev. Biol. - Plant 47, 3745 (2011) http://doi.org/10.1007/s11627-010-9303-X

16. R. de Carvalho Silva, Z. G. Luis, J. Everson Scherwinski-Pereira, Pesq. agropec. Bras 47(3), 344-350 (2012) https://doi.org/10.1590/S0100-204X2012000300005.

17. N. Doroshenko, V. Puzirnova, BIO Web Conf. 25, 04001 (2020) https://doi.org/10.1051/bioconf/20202504001

18. R.F. El-Hawaz, J. Adelberg, J. Naylor-Adelberg et al., In Vitro Cell.Dev.Biol.-Plant 55, 433-441 (2019) https://doi.org/10.1007/s11627-019-09996-0

19. H. Alzubi, L.M. Yepes, M. Fuchs, In Vitro Cell.Dev.Biol.-Plant 55, 334-341 (2019) https://doi.org/10.1007/s11627-019-09980-8

20. S. A. Hassanen, A.I.A. Abido, M.A.M. Aly, G.A. Rayan, African Journal of Basic \& Applied Sciences 5(2), 55-63 (2013) 